\title{
a-Si:H/CuInS ${ }_{2}$ heterojunctions for photovoltaic conversion
}

\author{
SATYENDRA KUMAR, A N TIWARI, O S SASTRY, D K PANDYA \\ and K L CHOPRA
}

Department of Physics, Indian Institute of Technology, New Delhi 110016, India

\begin{abstract}
Heterojunctions of hydrogenated a-Si films prepared by r.f. sputtering with spraypyrolyzed $\mathrm{CuInS}_{2}$ films have been studied. Capacitance-voltage measurements establish the formation of abrupt heterojunction. The barrier height varies from 0.26 to $0.55 \mathrm{~V}$ as the resistivity of CulnS $S_{2}$ film decreases from $1.5 \times 10^{3}$ to $65 \Omega \mathrm{m}$. These junctions exhibit photovoltaic behaviour with $V_{\mathrm{oc}}=220 \mathrm{mV}$ and $I_{\mathrm{sc}}=0.20 \mathrm{~mA} / \mathrm{cm}^{2}$.
\end{abstract}

Keywords. Heterojunction; a-Si: $\mathrm{H} ; \mathrm{CuInS}_{2}$; photovoltaics

\section{Introduction}

Hydrogenated a-Si is a promising material for low cost and large area solar cells. The main photogenerated carrier transport mechanism in an a-Si: $\mathrm{H}$ solar cell is drift of carriers, which depends on the strength and distribution of electric field in the i-layer of $\mathrm{p}-\mathrm{i}-\mathrm{n}$ junction. Further, because of the relatively short carrier diffusion length, the optimum thickness of the i-layer is restricted to $0.5-0.7 \mu \mathrm{m}$ although the penetration depth of $1.8 \mathrm{eV}$ photons (for the same band gap of a-Si:H) is around $5.0 \mu \mathrm{m}$. One of the major limitations in attaining higher efficiency in such cells is the loss of optical radiations because of the large bandgap and small thicknesses used for the fabrication of solar cells. Also, the cells have poor response at higher wavelengths. Attempts to make low band gap a-Si:H with tolerably low density of gap states have been unsuccessful as there appears a correlation between optical bandgap and disorder in the material. To improve the performance of the solar cell, effective utilization of unabsorbed high energy photons $\left(>E_{\theta}\right)$ and that of low energy photons $\left(<E_{\theta}\right)$ is required. One way to improve upon the efficiency of a-Si solar cell is to utilize optical and carrier confinement by employing highly reflecting back electrode and semitextured back surface. Solar cells having efficiency $\sim 9.3 \%$ have been achieved (Hamakawa and Okamoto 1984) using such principles. Another promising way is to use the concept of tandem cells of varying bandgap. Theoretically more than $20 \%$ efficiency can be achieved for two stacked cells (Fan and Palm 1983). Hamakawa and Okamoto (1984) developed ITO/n-i-p-a-Si:H/n-a-Si:H/poly c-Si/Ag stacked solar cell having $12.5 \%$ efficiency. Since the device is fabricated on Si wafer, it is not cost-effective. However, if thin films of semiconductors having optimum bandgap $(\sim 1.5 \mathrm{eV})$ are used, cost-effective high efficiency devices are expected. Among many others, $\mathrm{Cu}$-based chalcopyrite compound semiconductors $\mathrm{CuInX}_{2}$ (where $\mathrm{X}=\mathrm{S}, \mathrm{Se}, \mathrm{Te}$ ), are promising because of high absorption coefficient and bandgap in the range of $\sim 1.0-1.5 \mathrm{eV}$, valence controllability ( $p$ - or $n$-type) with control on varying electrical parameters and producibility of large area of films. A heterojunction of this material with a-Si:H would make best use of their optimum material properties for efficiency improvement. To 
achieve this an understanding of the material and its junction behaviour is essential.

With this in view, we have prepared junctions of $p$-CuInS $\mathrm{S}_{2}$ with a-Si: $\mathrm{H}$ in the structure $\mathrm{Al} / \mathrm{p}-\mathrm{CuInS} / \mathrm{a}-\mathrm{Si}: \mathrm{H} / \mathrm{SnO}_{x}: \mathrm{F} /$ glass. This paper describes the junction behaviour of such devices.

\section{Experimental details}

Films of a-Si:H (bandgap $1.8 \mathrm{eV}$ and resistivity $\sim 10^{8} \Omega \mathrm{m}$ ) were deposited by r.f. sputtering on $\mathrm{SnO}_{x}: \mathrm{F}$ coated glass substrates of sheet resistance $\sim 10 \Omega / \square$ acting as back electrode. p-CuInS $S_{2}$ films were deposited by spray pyrolysis (Tiwari et al 1985). Resistivity of the sprayed $\mathrm{CuInS}_{2}$ films can be varied by changing the $\mathrm{Cu} / \mathrm{In}$ ratio in the spray solution. The substrate temperature for this deposition was kept at $\sim 200-250^{\circ} \mathrm{C}$, ensuring that during the deposition of $\mathrm{CuInS}_{2}$ film there is no hydrogen evolution from the hydrogenated a-Si film. At this stage annealing in inert ambient is carried out at $250^{\circ} \mathrm{C}$ for 45 minutes and finally $\mathrm{Al}$ is evaporated on $\mathrm{CuInS}_{2}$ to make the top contact.

The frequency dependence of capacitance was measured using an LCR bridge for low frequencies and a Wayne-Kerr bridge for higher frequencies ( $>10 \mathrm{kHz}$ ). An automatic $\mathrm{C}-\mathrm{V}$ plotter was used to plot the capacitance-voltage characteristics of the junction at $100 \mathrm{kHz}$. The $\mathrm{C}-\mathrm{V}$ at $1 \mathrm{MHz}$ was measured using an msI junction profiler model 893. The current-voltage characteristics (I-V) of the junctions were plotted using an automatic I-V plotter. For light I-V an ORIEL solar simulator having intensity $\sim 100 \mathrm{~mW} / \mathrm{cm}^{2}$ was used. Details of the experimental set-up have been described elsewhere (Purushotam et al 1982, 1985).

\section{Results and discussion}

In order to study the nature of traps, the frequency dependence of capacitance was measured from $100 \mathrm{~Hz}$ to $1 \mathrm{MHz}$. Figure 1 shows the results. At $500 \mathrm{~Hz}$, the measured

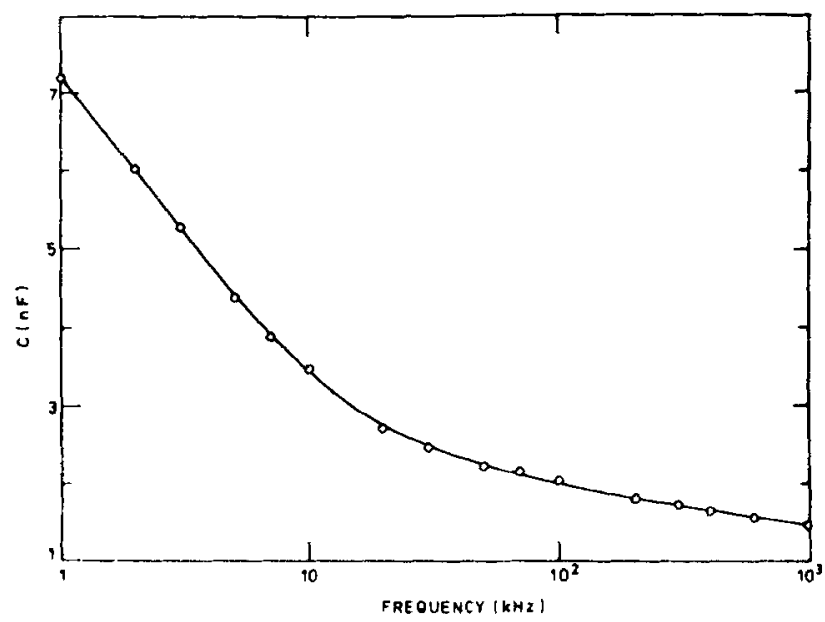

Figure 1. Frequency dependence of capacitance for a typical junction. 
capacitance was $90 \mathrm{nF}$ and it varied almost linearly with $\log f$ in the region 1 to $10 \mathrm{kHz}$ and $30 \mathrm{kHz}$ to $1 \mathrm{MHz}$ implying that the time constant of traps is varying indicating a band of deep donor levels with the response time having an exponential distribution. At higher frequencies $(f>1 / \tau)$, deep traps respond very slowly but the shallow traps having fast response time respond to the applied a.c. voltage and the capacitance decreases. As the frequency of a.c. signal decreases, deep traps start responding, causing shielding of the bulk traps (shallow) and dielectric relaxation, thus increasing the capacitance. Note that frequencies $\gtrsim 100 \mathrm{kHz}$ are high enough to neglect dielectric relaxation phenomena and thus $C-V$ characteristics can be studied for the evaluation of depletion layer width, $\omega$, and barrier voltage, $V_{b}$.

Figure 2 shows the variation of $1 / C^{2}$ and $\omega^{2}$ with bias voltage of junctions 0.5 and $0.32 \mu \mathrm{m}$ thick a-Si:H films with a $\mathrm{CuInS}_{2}$ (resistivity $1.5 \times 10^{3} \Omega \mathrm{m}$ ) film. We see that $1 / C^{2}$ varies almost linearly with reverse bias establishing the formation of abrupt junction. For $0.32 \mu \mathrm{m} \mathrm{a-Si}: \mathrm{H}$ film junction, deviation from linear behaviour is observed above $2.5 \mathrm{~V}$ because the whole of a-Si:H is depleted at this voltage and breakdown is expected. Another interesting aspect is the sublinearity in the forward bias region. This could be because of the interface states introduced during the junction formation. Figure 3 shows the $\omega^{2}$ vs bias voltage for three junctions with $\mathrm{CuInS}_{2}$ of $1.5 \times 10^{3}, 3.6$ $\times 10^{2}$ and $65 \Omega \mathrm{m}$ resistivities and a-Si:H film of $\sim 0.5 \mu \mathrm{m}$ thickness. We have calculated the donor density $\left(N_{D}\right)$ and barrier height from the slope and intercept of these curves. The calculated carrier density ranges from 3.1 to $6.8 \times 10^{22} \mathrm{~m}^{-3}$ and the barrier height varies with the resistivity of $\mathrm{CuInS}_{2}$ films from 0.26 to $0.55 \mathrm{~V}$. Junctions made with $\lesssim 10 \Omega \mathrm{m}$ resistivity show insignificant bias dependence and sometimes give unusually high $V_{b}(\gtrsim 1.0 \mathrm{~V})$.

I-V characteristics of the sample indicate that a good rectifying junction between a-Si:H and $\mathrm{CuInS}_{2}$ is formed. As-deposited samples show some hysteresis which vanishes in annealed samples. It is observed that series resistance decreases with decreasing $\mathrm{CuInS}_{2}$ resistivity but the samples made with lower resistivity $\mathrm{CuInS}_{2}$ films $(\lesssim 10 \Omega \mathrm{m}$ ) always show capacitive-type hysteresis behaviour although in such samples the series resistance is relatively low $(\lesssim 100 \Omega)$ with high rectification. The junctions show photovoltaic behaviour when illuminated under light. Figure 4 shows the light I$\mathrm{V}$ of samples 1 and 3, dark I-V of sample 3 is also included. The cross-over of light and

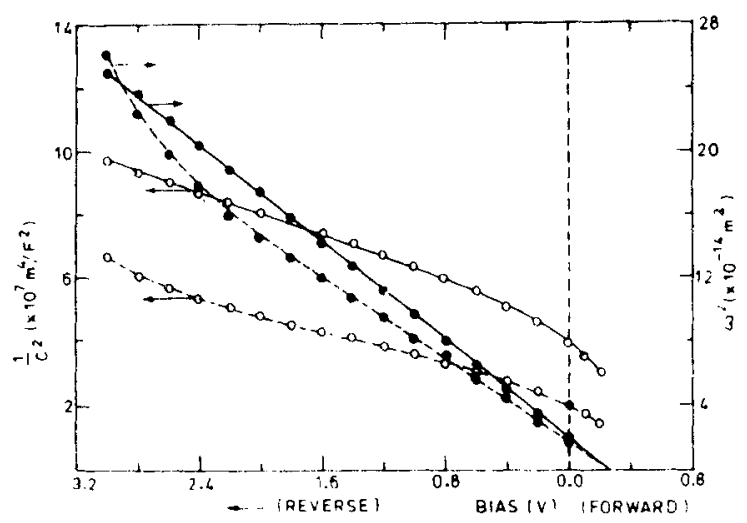

Figure 2. Variation of $l^{\prime}\left({ }^{2} \mathrm{C} O\right)$ and $\omega^{2}$ (O) with bias voltage for $0.5 \mu \mathrm{m}(\ldots \ldots)$ and $0.32 \mu \mathrm{m}(\ldots . . .-\ldots)$ thick a-Si: $\mathrm{H}$ film. 


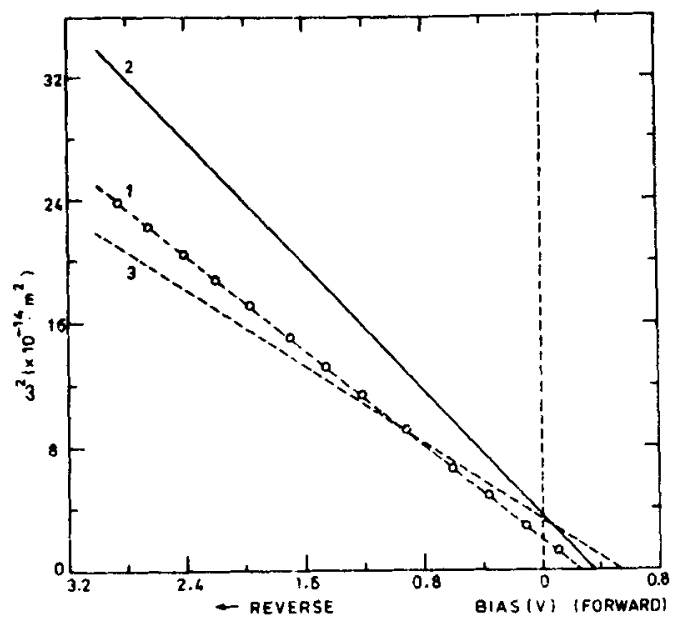

Figare 3. Variation of $\omega^{2}$ with bias voltage for junctions with different $\mathrm{CuInS}$ resistivities. 1. $1.5 \times 10^{3} \Omega \mathrm{m} ; 2.3 .6 \times 10^{2} \Omega \mathrm{m}$ and $3.65 \Omega \mathrm{m}$.

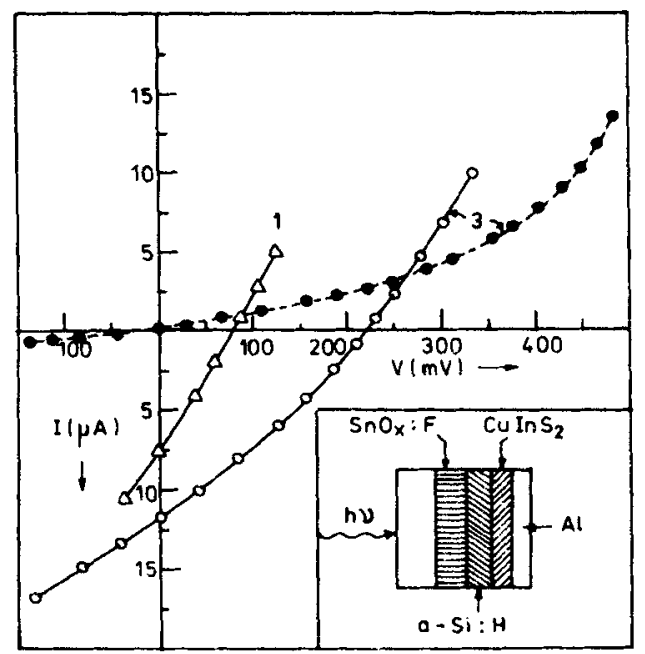

Figure 4. Current-voltage characteristics of junctions 1 and 3 (as described in figure 3). Inset shows the structure of the junction.

dark I-V may be because of photoconductivity of a-Si: $\mathrm{H}$. Spectral response measurements show a broad peak from 0.6 to $0.87 \mu \mathrm{m}$. Detailed analysis of the junction behaviour and its photoresponse analysis will be published separately (Tiwari et al 1985).

\section{Conclusions}

(i) Rectifying junctions have been formed between a-Si: $\mathrm{H}$ and $\mathrm{CuInS}_{2}$.

(ii) Barrier voltage of the junction is found to depend on the resistivity of $\mathrm{CuInS}_{2}$ 
films and increases from 0.26 to $0.55 \mathrm{~V}$ on decreasing the resistivity of CulnS $\mathrm{S}_{2}$ films from $1.5 \times 10^{3} \Omega \mathrm{m}$ to $65 \Omega \mathrm{m}$.

(iii) Junctions show photoresponse which depend on the resistivity of $\mathrm{CuInS}_{2}$ films. $V_{\mathrm{oc}}=0.22 \mathrm{~V}$ and $I_{\mathrm{sc}}=0.2 \mathrm{~mA} / \mathrm{cm}^{2}$ have been observed in good junctions.

\section{References}

Fan J C C and Palm B J 1983 Solur Cells 1081

Hamakawa Y and Okamoto H $1984 J p n$ Annu. Rev. Electron. Comput. Telecommun.; Amorphous semiconductor technologies and devices (ed.) Y Hamakawa 16208

Purushotam M, Mukerjee A K and Chopra K L 1982 Rev. Sci. Instrum. 531749

Purushotam M. Mukerjee A K and Chopra K L 1985 Indian J. Pure Appl. Phys. (accepted)

Tiwari A N. Pandya D K and Chopra K L 1985 Thin Solid Films (accepted)

Tiwari A N, Kumar S, Sastry O S. Pandya D K and Chopra K L 1985 (to be communicated)

Uchida K 1984 Jpn. Annu. Rev. Electron. Comput. Telecommun.; Amorphous semiconductor technologies and devices (ed.) Y Hamakawa 16186 